\title{
FITOCENOLOGIJA V SLOVENIJI SKOZI ČAS \\ PHYTOCENOLOGY IN SLOVENIA OVER TIME
}

Mitja Zupančič ${ }^{1}$

http://dx.doi.org/10.3986/fbg0035

\section{IZVLEČEK}

Fitocenologija v Sloveniji skozi čas

Opisan je razvoj fitocenologije v Sloveniji od njenega začetka med obema svetovnima vojnama do danes. Pionirji raziskovanj na področju fitocenoloških raziskovanj so bili Gabrijel Tomažič, Marko Zalokar, Maks Wraber in Vlado Tregubov. V vsem obdobju je delovalo 20 fitocenologov in 10 do 15 občasnih kartircev vegetacije.

Ključne besede: fitocenologija, zgodovina, Slovenija.

\section{ABSTRACT \\ Phytocenology in Slovenia over time}

The development of phytocenology in Slovenia is described from its beginnings between the two world wars to today. The pioneers of research in the field of phytocenology were Gabrijel Tomažič, Marko Zalokar, Maks Wraber and Vlado Tregubov. Twenty phytocenologists and 10 to 15 vegetation mappers worked over the course of the whole period.

Keywords: phytocenology, history, Slovenia

1 SAZU, Novi trg 5, 1000 LJUBLJANA 
Za razvoj fitocenologije so pomembna fitogeografska raziskovanja rastlinskega geografa A. Humbolta v začetku 19. stoletja, ki je planet Zemljo razdelil na fitogeografske pasove in posredno uvedel pojem asociacije (MARINČEK et al. 1972). V Evropi se je veda o rastlinskih združbah močno razvila. Med njenimi dosežki je bil najpomembnejši novodobni razvoj srednjeevropsko-züriško-montpellierske metode (šole) ustanovitelja Schröterja s pomembnim predstavnikom Braunom-Blanquetom, ki je moderno fitocenologijo preusmeril iz floristično-fiziognomske $\mathrm{v}$ floristično-ekološko smer (BRAUn-Blanquet 1921, MARINČEK et al. 1972). Precej odmevna je bila tudi uppsalska metoda, ki jo je zastopal Du RieTz (1921), vendar pri nas ni bila sprejeta. Na Hrvaškem sta jo prevzela Ivo Horvat in Stjepan Horvatić pri začetnih fitocenololoških raziskovanjih, ki sta jo kasneje opustila in prešla na züriško-montpelliersko metodo (Petкovšek 1934 man.). Prvi slovenski raziskovalci vegetacije Gabrijel Tomažič, Marko Zalokar, Maks Wraber, Vlado Tregubov in Viktor Petkovšek so sprejeli novo metodo, jo spremljali, dopolnjevali in jo posredovali mlajšim kolegom.

Prva fitocenološka raziskovanja v Sloveniji so potekala med obema vojnama. V tem obdobju je bil najzaslužnejši G. Tomažič, ki se je sprva posvečal genetiki, pozneje pa je prešel na področje fitocenologije. Preučeval je borove gozdove in travišča iz razreda Arrhenatheretalia (red pašnikov in travnikov na rodovitnih mineralnih tleh). Zanimivo je njegovo delo pri pripravi rokopisne vegetacijske karte Golovca (1928-1932), ki je bila najverjetneje prva te vrste na Balkanu. Ob koncu tridesetih let prejšnjega stoletja je jezerske, morske in plevelne združbe raziskoval M. Zalokar, ki se je pozneje osredotočil na zoofiziološke raziskave. M. Wraber, ki je doktoriral s področja rastlinske morfologije oz. organografije rodu Riella, se je nato preusmeril v fitocenologijo in bil v letih 1935-1936 na študijskem izpopolnjevanju in specializaciji iz fitocenologje pri Braunu-Blanquetu v Montpellieru. V tem obdobju je raziskoval tamkajšnjo mediteransko združbo hrasta Quercus coccifea. Leta 1934 je V. Petkovšek v tipkopisu pripravil primerjalno študijo Braun-Blanquet ali du Rietz«. Verjetno gre za profesorsko nalogo. Nato se je predvsem posvetil floristiki in se kasneje pojavil kot predavatelj fitocenologije za gozdarje v šolskem letu 1953-1954 in pozneje kot raziskovalec traviščne vegetacije.

Hiter razvoj je fitocenologija doživela po drugi svetovni vojni $z$ ustanovitvijo dveh gozdarskih inštitutov, zveznega in republiškega, ter gozdarskega oddelka na Fakulteti za agronomijo in gozdarstvo v Ljubljani pred sedemdesetimi leti. Za razvoj fitocenologije na področju gozdarstva imajo zasluge predvsem gozdar
V. Tregubov ter biologa M. Wraber in G. Tomažič. V prvih dveh letih po drugi svetovni vojni - pa tudi pozneje - je bil organizacijsko najbolj prizadeven V. Tregubov, ki je na obeh inštitutih, ki sta se kmalu združila, s pomočjo M. Wraberja vpeljal fitocenološka preučevanja gozdne vegetacije. Verjetno pa je prav V. Tregubov predlagal profesorju Stanku Sotošku, enemu izmed ustanoviteljev gozdarskega oddelka na tedanji fakulteti, predmet oz. študij fitocenologije za gozdarje. V. Tregubov je imel v času (1944-1945) partizanstva na Visu nalogo izdelati koncept študija gozdarstva v povojni Jugoslaviji. Predavanja iz fitocenologije za gozdarje je prevzel že habilitirani učitelj botanike G. Tomažič, ki je imel bogate izkušnje na tem področju, zlasti z objavo razprav o borovih gozdovih Slovenije (ToMAŽIČ 1940, 1942). G. Tomažič in M. Wraber sta bila domačina, V. Tregubov je prišel iz Bosne, kjer je pred drugo svetovno vojno raziskoval tamkajšnjo vegetacijo omorike ter gozdov jelke in bukve. G. Tomažiča, M. Wraberja, V. Tregubova, V. Petkovška in M. Zalokarja uvrščamo med pionirje fitocenoloških raziskav v Sloveniji. Pomemben pečat fitocenološki stroki so zlasti dali G. Tomažič, M. Wraber in V. Tregubov. M. Wraber se je osredotočil na raziskave pohorskih gozdov (M. Wraber 1955) in Slovenskega primorja (M. WRABER 1963), V. Tregubov bukovih gozdov slovenskega dinarskega gorstva (Tregubov 1957), pri čemer se je srečal s podobnimi raziskavami G. Tomažiča na Snežniku, ter s preučevanjem alpskega bukovega gozda (TREgubov 1957a). G. Tomažič je s prihodom na gozdarski oddelek Fakultete za agronomijo in gozdarstvo dal idejo za fitocenološko preučevanje gozdov tedanjega fakultetnega posestva v Kamniški Bistrici. Terenske raziskave je zaupal mlajšemu kolegu iz druge generacije fitocenologov, asistentu Stanku Cveku na katedri za gojenje gozdov, že izoblikovanemu fitocenologu. S. Cvek je med študenti poiskal primerne sodelavce, med katerimi je izstopal Živko Košir, ki je imel pozneje vidno vlogo pri preučevanju in kartiranju gozdne vegetacije. V. Tregubov pa si je za sodelovanje pri raziskavah in kartiranju gozdne vegetacije izbral biologa Ignaca Persoglia in Milana Piskernika. Ti so bili pozneje vodilni raziskovalci druge generacije fitocenologov.

Do leta 1960 sta bili vodilni ustanovi za preučevanje in kartiranje gozdne vegetacije Gozdarski inštitut Slovenije oz. Inštitut za gozdno in lesno gospodarstvo Slovenije ter gozdarski oddelek Fakultete za agronomijo in gozdarstvo (danes Biotehniška fakulteta). Namen gozdnovegetacijskih raziskav je bil predvsem praktične narave, kot pomoč in osnova za gozdnogospodarsko načrtovanje naravne obnove gozdov v skladu $\mathrm{z}$ rastiščnimi zakonitostmi. Ob tem so nastale tri pomembne študije, in sicer razprava o prebiralnih gozdo- 
vih jelke in bukve na Snežniku (Tregubov 1957), ter provizorična fitocenološka elaborata o gozdovih Kamniške Bistrice (Cvek 1955) in o vegetacijskih združbah pohorskih gozdov WraberJa (1956), ki je bil osnova za nadaljnje raziskave.

Zaradi nepričakovanih nesoglasij med tremi vodilnimi fitocenologi prve generacije so nekoliko zastale obširnejše vegetacijske raziskave, ki so ponovno stekle po letu 1954. V tem času (1954) pa je Piskernik opustil srednjeevropsko metodo raziskovanja vegetacije ter je začel uporabljati drugačne pristope oziroma raziskovalno smer, ki so jo poimenovali »inštitutska metoda" (Zupančič 1997). Izhajal je iz utemeljenega stališča, da je vegetacija kontinuum, ker se gozdne združbe $\mathrm{v}$ prostoru med seboj prepletajo, meje med njimi pa so nejasne ali celo neugotovljive (SMOLE \& KUTNAR 1997). Njegova metoda temelji na mikrorelifnih združbah, ki jih je mogoče po njegovem sistemu mnogo bolje omejiti kot po srednjeevropski metodi. Metoda izhaja iz različnih posamičnih ekoloških dejavnikov: enkrat iz temperature, drugič iz padavin ipd. Mnenje nekaterih fitocenologov je, da M. Piskernik v svoji metodi združuje določene elemente uppsalske metode, metode talnovegetacijskih tipov, metode višinskih tipov in srednjeevropske metode (MARINČEK et al. 1972, ZupančIČ 1997). M. Piskernik si je zelo prizadeval za uveljavitev svoje metode, zato je objavil več razprav, ki pa niso naletele na želeni odmev ne doma, še manj v tujini. Njegovi metodi je sledil Karl Hauser, ki je deloval v gozdnogospodarskem območju v Slovenj Gradcu. Njegovo metodo so krajši čas uporabljali tudi v gozdnogospodarskem območju Bled.

Po letu 1954 se je M. Wraber zaposlil na Inštitutu za biologijo SAZU (danes Biološki inštitut Jovana Hadžija ZRC SAZU), kjer je preučeval gozdno vegetacijo za tedanje potrebe gozdarske operative in izdeloval orientacijske fitocenološke elaborate brez vegetacijskih kart. Ob teh opisih gozdne vegetacije se je posvečal sinsistematskim raziskavam novih gozdnih združb. Tako so nastale študije o združbah gozdov smreke in gozdne bekice, jelke in okroglolistne lakote ter grmišča črnega gabra in žarkaste košeničice (M. WRABER 1959, 1961, 1963a).

V. Tregubov je za krajši čas odšel v tujino, kjer je preučeval gozdno vegetacijo Atlasa, in se leta 1954 vrnil v Slovenijo. Ob vrnitvi mu je S. Sotošek ponudil dveletni projekt o melioraciji in obnovi zgornjesavskih gozdov v povezavi z negativnimi posledicami za naravo ob gradnji hidroelektrarne Moste pri Žirovnici in po njej. Projekt je naročil Okrajni ljudski odbor za Radovljico. $\mathrm{V}$ tem projektu so združili moči fitocenologi V. Tregubov, G. Tomažič, S. Cvek, I. Persoglio in Ž. Košir ter k sodelovanju pritegnili absolvente gozdar- stva Dušana Robiča, Lojzeta Marinčka in Mitja Zupančiča, ki so pozneje predstavljali jedro tretje generacije fitocenologov, tej pa so se pridružili Tone Wraber, Ivo Puncer, Andrej Martinčič, Vinko Žagar, Milan Prešeren in France Šuštar.

Po opravljenem delu v Zgornjesavski dolini z izdelavo obširnega elaborata, utemeljenega na ekoloških načelih fitocenoloških raziskav, je V. Tregubov spet dobil mesto fitocenologa na Gozdarskem inštitutu, $\mathrm{k}$ sodelovanju pa je povabil M. Zupančiča. Tako sta bili na inštitutu prisotni dve metodi oz. smeri fitocenoloških raziskav, in sicer M. Piskernikova inštitutska ter standardna srednjeevropska ali Braun-Blanquetova metoda. M. Piskernik je po svoji metodi raziskoval vso vegetacijo v Sloveniji, za operativne potrebe gozdarstva pa blejsko in predvsem koroško območje, kjer je z njim sodeloval tamkajšnji fitocenolog K. Hauser. Na blejskem gozdnogospodarskem območju sta se srečevali obe metodi: srednjeevropska (V. Tregubov) in inštitutska (M. Piskernik). Raziskave so vzporedno potekale po dveh metodah. Glavnina preučevanj V. Tregubova v različnih časovnih obdobjih $\mathrm{z} \mathrm{M}$. Zupančičem pa je bila usmerjena na postojnsko in ljubljansko gozdnogospodarsko območje.

Podobno se je zgodilo pri preučevanju gozdne in grmiščne vegetacije slovenske Istre, ki jo je po srednjeevropski metodi raziskoval M. Wraber in M. Piskernik po svoji metodi.

Šestdeseta leta prejšnjega stoletja so prinesla nov zagon na področju fitocenoloških raziskav. Leta 1962 je bila ustanovljena botanična oz. fitocenološka skupina na Inštitutu za biologijo SAZU (danes Biološki inštitut Jovana Hadžija ZRC SAZU), ki jo je do svoje smrti leta 1972 vodil M. Wraber, po njem pa do leta 1991 M. Zupančič, za njim pa A. Čarni s sodelovanjem L. Marinčka. Sodelavci so bili Ivo Puncer, Vinko Žagar, Milan Prešeren, s prekinitvami Marko Accetto ter pozneje Andrej Seliškar in Lojze Marinček ter občasno študenti gozdarstva in biologije naj navedemo najbolj stalne sodelavce: Andrej Capuder, Drago Jordan, Zdravko Keglevič, Marjan Lipoglavšek, Jože Papež, Marjan Štempihar, Boris Turk idr. Naloga te skupine je bila dvojna: primarna zadolžitev je bila reševanje teoretičnih vprašanj sintaksonomske, sinekološke, sinhronološke, sinhorološke in fitogeografske narave za vso vegetacijo Slovenije v primerjavi s podobnimi evropskimi raziskavami, zlasti z vzhodnoalpsko-dinarskem območjem. Druga smer je bila praktičnega značaja: to so bile podrobne ekološke raziskave na podlagi fitocenologije in pedologije za operativne namene pri načrtovanju gojenja in urejanja gozdov $\mathrm{z}$ izdelavo vegetacijskih kart $\mathrm{v}$ večjih merilih (1:10.000, $1: 25.000)$. 
V letu 1961 je bila ustanovljena fitocenološka skupina pri Biroju za gozdarsko načrtovanje pod vodstvom direktorja biroja Ž. Koširja in pozneje L. Marinčka. Glavna naloga skupine je bila preučevanje in kartiranje gozdne vegetacije $\mathrm{v}$ merilih $1: 10.000 \mathrm{z}$ izdelavo elaboratov na podlagi ekoloških dejavnikov za potrebe gozdnogojitvenih in urejevalnih dejavnosti v posameznih gozdnih območjih. Skupino so poleg vodij sestavljali še Dušan Robič, Marko Accetto, Ivan Smole, Marja Zorn, Marjan Šolar, Niko Torelli, Boštjan Anko, Evgenij Azarov, Lojze Čampa, Mihej Urbančič, Lojze Žgajnar idr.

Šesto desetletje je zlasti pomembno s pričetkom dveh velikih projektov, izdelave realne in potencialne naravne karte vegetacije Jugoslavije in Slovenije. Leta 1960 je bil na pobudo hrvaškega fitocenologa Iva Horvata s sodelovanjem Stjepana Horvatića in vodilnih fitocenologov iz drugih republik Maksa Wraberja in Vlada Tregubova (Slovenija), Vilotije Blečića (Črna gora), Hansa Ema (Makedonija), Pavla Fukareka (Bosna in Hercegovina) ter Brana Jovanovića in Vojeslava Mišića (Srbija) predlagan projekt za izdelavo vegetacijskih kart v merilu $1: 100.000$ in $1: 1.000 .000$. Projekt je dejansko stekel leta 1962. V Sloveniji sta ga vodila $\mathrm{M}$. Wraber (do svoje smrti) in pozneje $\mathrm{M}$. Zupančič, ki je bil v letih 1986-89 predsednik programskega sveta Vegetacijske karte Jugoslavije, in od leta 1984-89 njen glavni redaktor.

Leta 1965 so začeli izvajati projekt Gozdnovegetacijska karta Slovenije v merilu 1: 100.000, njegov namen pa je bil ekološke vrednotenje gozdne vegetacije. Vodil ga je Ž. Košir.

Obdobje od šestdeset do osemdeset let je bilo najbolj plodno glede vegetacijskih raziskovanj Slovenije. Pri tem je imela pomembno vlogo Biotehniška fakulteta, ki je bila usmerjena predvsem na študij fitocenologije za gozdarje. Zaradi daljše G. Tomažičeve bolezni so bila predavanja večkrat prekinjena. Začasno jih je prevzel botanik in fitocenolog V. Petkovšek, dokler ni leta 1963 prišel na njegovo mesto fitocenolog D. Robič, ki je predavanja izvajal na zavidljivi didaktični in pedagoški ravni. Po D. Robičevi upokojitvi je predavanja prevzel fitocenolog M. Accetto. Danes predavata fitocenologa Igor Dakskobler in Andrej Rozman. Na agronomskem oddelku Biotehniške fakultete (BF) ni bilo večjega zanimanja za fitocenološke raziskave. Biologa V. Petkovšek in F. Šuštar sta predstavljala program za preučevanje travišč glede na zmožnosti pospeševanja beljakovinsko donosnejših trav in drugih zelišč.

$\mathrm{Na}$ biološkem oddelku Biotehniške fakultete je T. Wraber raziskoval alpska travišča in naskalno vegetacijo, A. Martinčič pa barja, največkrat s M. Piskernikovim sodelovanjem. Na Pedagoški fakulteti Univerze v
Mariboru se je botaničarka Ljerka Godicelj spogledovala s fitocenologijo, vendar je ta zaživela šele s prihodom Mitje Kaligariča in Sonje Škornik.

Omeniti moramo še kolega Mitja Cimpreška, ki je preučeval gozdove na obrobju predpanonske Slovenije, kjer je služboval (Gozdna uprava Rogaška Slatina).

Vodenje fitocenoloških raziskav sta $\mathrm{v}$ teh letih (1960-80) prevzela Biološki inštitut Jovana Hadžija ZRC SAZU in Biro za gozdarsko načrtovanje. Tu moramo opozoriti na razčlenjevanje bukovih makroasociacij na ekološko, floristično in posledično sintaksonomsko ustrezno oblikovane bukove združbe, opredeljene glede na njihovo višinsko pasovitost (npr. gozdna vegetacija na Gorjancih) Ž. Koširja. Tej sintaksonomski rešitvi smo sledili tudi drugi fitocenologi, ne le pri bukovih gozdovih, temveč pri vsej vegetaciji, zlasti gozdni in grmiščni.

Ob koncu šestdesetih let je M. Wraber (1969) objavil prvo fitogeografsko delitev Slovenije, in sicer na šest območij. Pozneje jo je izpopolnjeval M. Zupančič s sodelavci (Zupančič et al. 1987, Zupančič \& ŽAGAR 1995). Pozneje je Ž. Košir (1975) objavil delitev Slovenije na šest fitoklimaksnih teritorijev. Delitev šestih območij je pri obeh kartah precej podobna, največje razlike so v severovzhodnem delu Slovenije. Gre za obseg območja med preddinarskim in predpanonskim območjem.

Šestdeseta leta so bila pomembna tudi zaradi intenzivnega razmišljanja o uveljavitvi posebne ilirske flore $\mathrm{v}$ fitocenološki sinsistematiki. $\mathrm{V}$ raziskavah je bil poudarek na območju ilirske florne province, ki se razlikuje od srednjeevropske z ilirskimi ali ilirskoidnimi ali jugovzhodnoevropsko-ilirskimi vrstami. Že leta 1938 je o tem razmišljal I. Horvat, kar je formalno udejanjil z opisom zveze ilirskih bukovih gozdov leta 1950. Madžarski botanik in fitocenolog A. BorHidI (1963) pa je Horvatovo zamisel utemeljil z obširno razpravo o zvezi Fagion illyricum oz. današnjo Aremonio-Fagion. V zvezo so uvrščeni ilirski bukovi gozdovi, ki uspevajo $\mathrm{v}$ ilirski florni provinci. Ilirska flora pa je s posamezno vrsto ali vrstami včasih prisotna tudi v sintaksonih, ki so uvrščeni v neilirske sintaksone. Tako se je porodila zamisel o geografskih variantah določene asociacije po vzoru Oberdorferjevih ras (Oberdorfer 1957) ali višinskih pasov zakoncev Matuszkiewicz (1981). Tako se je sintakson sinsistematsko ločil od srednjeevropskega ali drugega fitogeografskega območja. To je posebej pomembno s teoretičnega vidika sinsistemtike in poznavanja pestrosti biodioverzitete. Manj pa je to pomembno za praktično uporabo, npr. $\mathrm{v}$ gozdnem gospodarstvu, vendar ne vedno. Nekatere geografske variante imajo le drugačne ekološke razmere kot osnovna tuja ali v drugem območju domača asociacija. Geo- 
grafske variante je uveljavila predvsem fitocenološka skupina Biološkega inštituta Jovana Hadžija ZRC SAZU, ki se večinoma ukvarja s temeljnimi, teoretičnimi fitocenološkimi raziskavami.

Leta 1981 se je fitocenološka skupina Biroja za gozdarsko načrtovanje priključila Gozdarskemu inštitutu (Inštitutu za gozdno in lesno gospodarstvo). Tam so nadaljevali $z$ vegetacijskim kartiranjem in raziskavami za gozdna gospodarstva ali za druga pomembna gospodarska načrtovanja na podlagi fitocenološke metode oziroma ekoloških rešitev. (SMOle \& Kutnar 1997).

$\mathrm{V}$ osemdesetih in devetdesetih letih je število članov fitocenološke skupine Biološkega inštituta ZRC SAZU povečalo s prihodom A. Čarnija in I. Dakskoblerja, pozneje so se pridružili še Aleksander Marinšek, Petra Košir, Urban Šilc in Igor Zelnik. Na Gozdarskem inštitutu Slovenije pa je bil ustanovljen Oddelek za gozdno ekologijo, ki ima danes trinajst sodelavcev (ANONYMUS 2017), med njimi se s fitocenološkimi raziskavami največ ukvarjata Lado Kutnar in Aleksander Marinšek.

Omeniti velja še, da so v sedemdesetih in osemdesetih letih na prošnjo Biološkega inštituta Jovana Hadžija ZRC SAZU aktivno sodelovali z raziskavami traviščnih in ruderalnih združb kolegi iz Botaničnega zavoda Zagrebškega vseučilišča akademik Stjepan Horvatić ter profesorja Ljerka Marković in Ljudevit Ilijanić. Bili so opora tedaj mlademu fitocenologu za negozdne združbe A. Seliškarju.

Po letu 1991 so z reformo gozdarskih služb v novo nastali državi Sloveniji naročila za ekološke vrednotenje gozdnih površin na podlagi fitocenologije usihala in dokončno usahnila. Poleg organizacijskih reform v gozdarstvu je temu botrovala še novejša evropska metodologija preučevanja habitatov oz. habitatnih tipov, ki se je pojavila že v osemdesetih letih prejšnjega stoletja. Habitati so prostorsko zaključene enote ekosistema (BATIČ et al. 2011), ki so ohlapnejše od vsestransko ekološko natančneje opredeljene fitocenoze po srednjeevropski metodi. Zaradi poenostavljenosti je metoda habitatov za večino naročnikov na splošno sprejemljivejša, tako glede ustreznega znanja naročnikov kot po finančni strani. Pri tovrstnih raziskavah sodelujejo Gozdarski inštitut Slovenije, Oddelek za gozdarstvo in obnovljive vire Biotehniške fakultete, Biološki inštitut Jovana Hadžija ZRC SAZU, in občasno ustrezne lokalne in državne organizacije. Kljub tem usmeritvam fitocenološke raziskave niso zamrle, je pa zamrlo vegetacijsko kartiranje.

Slovenski fitocenologi so poleg domačega ozemlja raziskovali vegetacijo $\mathrm{v}$ sosednjih državah, oziroma prejšnjih jugoslovanskih republikah zaradi primerjav, in sicer na lastno pobudo, s povabilom ali prek meddr- žavnih programov. M. Wraber je v Bosni preučeval kisloljubne bukove gozdove. V. Tregubov vegetacijo v Maroku in Iranu. M. Zupančič in V. Žagar v Makedoniji, Črni gori, Bosni in Hercegovini ter na slovenskem etničnem ozemlju Italije smrekove in bukove gozdove. A. Čarni je sam ali s sodelavci raziskoval gozdno in negozdno vegetacijo v Makedoniji, Turčiji in Grčiji. L. Marinček in M. Zupančič sta s sodelovanjem italijanskega kolega in prijatelja Livia Poldinija ter avstrijskega kolega in prijatelja Kurta Zukrigla raziskovala alpski bukov gozd $\mathrm{v}$ treh deželah $\mathrm{v}$ obmejnem prostoru severozahodne Slovenije, severovzhodne Italije in jugovzhodne Avstrije.

Ko si ogledamo sedemdesetletne rezultate fitocenoloških raziskav v Sloveniji, povejmo, da ima za razvoj fitocenologije na Slovenskem nedvomno največ zaslug gozdarstvo, zlasti $\mathrm{z}$ naročili vegetacijsko-ekoloških elaboratov za gozdna gospodarstva. Naročila teh elaboratov so zaživela s prizadevanjem Ž. Koširja za uresničitev predpisa ustreznega ministrstva, da morajo biti gojitveni in gozdnogospodarski načrti utemeljeni na vegetacijsko-ekoloških elaboratih $\mathrm{z}$ vegetacijskimi kartami v merilu $1: 10.000$ (v določenih primerih 1 : 5.000 ali $1: 25.000$ ).

Rezultati fitocenoloških raziskav in kartiranja se zrcalijo $\mathrm{v}$ izdelavi treh vegetacijskih kart, in sicer $\mathrm{v}$ danes digitalizirani Gozdnovegetacijski karti Slovenije v merilu $1: 100.000$ Biroja za gozdarska načrtovanja oz. Gozdarskega inštituta Slovenije (TAVČAr et al. 2002, izdelana 1973?), v karti potencialne naravne vegetacije SFR Jugoslavije v merilu $1: 1.000 .000$ Znanstvenega sveta vegetacijske karte Jugoslavije (1983-86), ki je bila izhodišče za karti naravne vegetacije Evrope (Karte der natürlichen Vegetation Europas) v merilih $1: 2.500 .000$ in $1: 10.000 .000$ (Bundesamt für Natruschutz, Bonn 2003), ter karte potencialne naravne vegetacije Slovenije v merilu $1: 200.000$ Biološkega inštituta Jovana Hadžija ZRC SAZU. V rokopisni obliki je še mnogo vegetacijskih kart $\mathrm{v}$ različnih merilih. Naj omenimo številne vegetacijske karte v merilu $1: 10.000$, ki so podlaga za številne vegetacijsko-ekološke elaborate namenjene za načrtovanje gojitvenih in urejevalnih ukrepov na ekološki osnovi.

Obdobje od sedemdesetih let do danes je znanstveno- in strokovno-publicistično najbogatejše in najuspešnejše. Znanstvene in strokovne razprave so prinesle mnoge novosti, ki niso pomembne le za nas, temveč tudi za vzhodnoalpsko-dinarsko območje in še širše za srednjeevropski prostor. Opisanih je mnogo novih sintaksonov, največ asociacij, pa tudi nižjih (subasociacij, variant) in višjih sinsistematskih stopenj (podzvez in zvez). Med mnogimi raziskovalci fitocenologi pri objavah v tem obdobju izstopajo M. Accetto, A. Čarni, I. 
Dakskobler, M. Kaligarič, P. Košir, Ž. Košir, L. Kutnar, L. Marinček, A. Marinšek, M. Piskernik, A. Seliškar, U. Šilc, S. Škornik, T. Wraber, I. Zelnik, M. Zupančič. Imenovani in drugi raziskovalci - fitocenologi so $\mathrm{v}$ sedemdeset letnem obdobju objavili številne publika- cije različnih bibliografskih enot od znanstvenih in strokovnih razprav do znanstvenih in strokovnih monografij ter elaboratov in poljudnoznanstvenih člankov, kar je večinoma razvidno na spletnih straneh (COBISS).

\section{LITERATURA}

ANONYMUS, 2017: Rastemo z gozdom (ur. Simončič, Režonja \& Železnik). Silva Slovenica, Gozdarski inštitut Slovenije. Ljubljana. Zbornik ob 70. obletnici GIS.

Batič, F., B. Košmrlj-Levačič, A. Martinčič, A. Cimerman, B. Turk, M. Gogala, A. Seliškar, A. Šercelj \& G. KosI, 2011: Botanični terminološki slovar. Zbirka Slovarji. ZRC SAZU. Ljubljana.

Borhidi, A., 1963: Die Zönologie des Verbandes Fagion illyricum. Acta Botanica Acadamiae scientiarum Hungaricae. (Budapest) 9: 259-297.

Braun-Blanquet, J., 1921: Prinzipen ist einer Systematik der Pflanzengesellschaften auf floristischer Grundlage. Jahrb. d. St. Call. naturw. Ges. Zürich.

CveK, S., 1955: Opis gozdnih združb doline Kamniške Bistrice s posebnim ozirom na gozdnogojitveno problematiko. Fakulteta za agronomijo in gozdarstvo. Ljubljana. (Rokopis).

Du Rietz, 1921: Zur methodelogischen Grundlage der modernen Pflanzen soziologie. Wien.

KošIR, Ž., 1975: Rastlinstvo (v Geološka in gozdnovegetacijska podoba. Gregorič V., J. Kalan \& Ž. Košir, v Gozdovi na Slovenskem ur. C. Remic) Borec \& Poslovno združenje gozdnogospodarskih organizacij (Ljubljana) 30-62.

Marinček, L., I. Puncer \& M. Zupančič, 1972: Razvojna pota preučevanja in kartiranja vegetacije Slovenije. Gozdarski vestnik (Ljubljana) 30 (5-6): 153-166.

Matuszkiewicz, W. \& A. Matuszkiewicz, 1981: Das Prinzip der mehrdimensionalen Gliederung der Vegetationseinheiten, erläutet am Beispiel der Eichen-Hainbuchen wälder in Polen. V: Dierschke, H. (ur.): Synataxonomie. Ber. Int. Symp. Int. Vereinig. Vegetationsk. Rinteln 1980: 123-148. Vaduz.

Oberdorfer, E., 1957: Süddeutsche Pflanzengesellschaften. Pflanzen soziologie 10. Jena

Petкovšek, V., 1934: Braun-Blanquet ali Du Rietz? Primerjanje in presoja dveh evropskih fitocenoloških šol. Ljubljana (manuskript).

Smole, I. \& L. Kutnar, 1997: Fitocenologija v polstoletni zgodovini Gozdarskega inštituta Slovenije (GIS). Znanje za gozd ob 50. obletnici obstoja in delovanja GIS. Ljubljana.

TavČAR, I., L. Kutnar \& T. KralJ, 2002: Digitalizacija gozdnovegetacijske karte Slovenije v M 1:100.000. Gozdarski inštitut Slovenije. Ljubljana.

Tomažıč, G., 1940: Asociacija borovih gozdov v Sloveniji. I. Bazifilni borovi gozdovi. Razprave matemat. - prirod. razreda AZU (Ljubljana) 1: 77-120.

Tomažıč, G., 1942: Asociacije borovih gozdov v Sloveniji. II. Acidofilni borovi gozdovi. Razprave matemat. - prirod. razreda AZU (Ljubljana) 2: 161-240.

Tregubov, V. \& M. Čokl (urednika), 1957: Prebiralni gozdovi na Snežniku. Inštitut za gozdno in lesno gospodarstvo. Strokovna in znanstvena dela 4. Ljubljana.

Tregubov, V. 1957a (ur.): Elaborat za osnovo gojitvenega in melioracijskega načrta gozdov, gozdnih zemljišč in pašnikov za področje Zgornje savske doline. Kranj.

Wraber, M., 1955: Tipi gozdne vegetacije na Pohorju. Inštitut za gozdno in lesno gospodarstvo Slovenije. Ljubljana. (Tipkopis).

Wraber, M., 1959: Gozdna združba jelke in okroglistne lakote v Sloveniji (Galieto rotundifolii - Abietetum Wraber 1955). Prirodoslovno društvo v Ljubljani. Ljubljana.

Wraber, M., 1961: Termofilna združba gabrovca in omelike v Bohinju (Cytisantho - Ostryetum Wraber assoc. nova). Razprave IV. razreda SAZU (Ljubljana) 6: 7 - 50 + tab.

Wraber, M., 1963: Allgemeine Orientirungskarte der potentiellen natürlichen Vegetation im Slowenischen Küstenland (NW Jugoslawien) als Grundlage für die Wiederbewaldung der degradierten Karst- und Flyschgebiete. Ber. Int. Symp. f. Vegetationskart 1959: 369-384, Weinheim. 
Wraber, M., 1963a: Gozdna združba smreke in gozdne bekice v slovenskih Vzhodnih Alpah (Luzulo silvaticae- Piceetum Wraber 1953). Razprave IV. razreda SAZU (Ljubljana) 7: $79-175+$ tab.

Zupančič, M., L. Marinček, A. SelišKar \& I. Puncer, 1987: Considerations on the phytogeographic division of Slovenia. Biogeographia 13. Biogeografija Alpi-Sud-Orientali (Udine): 89-98.

ZuPANČIČ, M., \& V. ŽAGAR, 1995: New views about the phytogeographic division of Slovenia, I. Razprave IV. razreda SAZU (Ljubljana) 36: 3-30.

Zupančič, M., 1997: Pregled fitocenoloških raziskav v Sloveniji. Acta Biologica Slovenica (Ljubljana) 41 (2-3): 5-17.

\section{SUMMARY}

Forestry has been of great importance for the development of phytocenological science in Slovenia, having supported such research of forest areas in Slovenia. The research was and is still done according to the standard Central European, Zurich-Montpellier school. Some vegetation studies have also done according to Piskernik's ,institutional method.“"

The first phytocoenological studies in Slovenia were already being performed between the two world wars. Of the then researchers, Gabrijel Tomažič stands out with a publication on pine forests and grasslands. Phytocenology made significant progress after World War II, with the founding of the Forestry Institute of Slovenia (GIS) and the forestry department of the then Faculty of Agronomy and Forestry. Those responsible were the pioneers of the profession, Gabrijel Tomažič, Maks Wraber and Vlado Tregubov. Until the 1960s, phytocoenological research was conducted under the auspices of the GIS and the Faculty of Forestry. After this period, two phytocoenological groups were formed: at the Forestry Planning Bureau (1961) and then at the then Institute of Biology SAZU (1962). The research was mostly carried out on forest management organization, as the established ecological basis for cultivation and management plans. Basic research was carried out in parallel, but to a lesser extent. During this period, a number of studies were prepared with vegetation maps, mostly to a scale of $1: 10,000$. The rapid development of phytocoenological research enabled the realization of plans for a potential natural vegetation map of Yugoslavia (SAZU 1962) on a scale of 1: 1,000,000 and forest vegetation maps for the ecological evaluation of forest vegetation (Biro 1965, after 1975 GIS) on a scale of 1: 100,000. In addition to these two maps, many younger phytocenologists came to maturity under the guidance of the three aforementioned pioneers and Stanko Cvek, Ignac Persoglio and Živko Košir. These were: Dušan Robič, Mitja Zupančič, Lojze Marinček and Ivo Puncer, and later Marko Accetto, Ivan Smole, Andrej Seliškar, Marja Zorn, Vinko Žagar, Marjan Šolar etc.

Education at the Faculty of Forestry was first provided by Gabrijel Tomažič, later Viktor Petkovšek, then Dušan Robič, Marko Accetto and today Andrej Rozman and Igor Dakskobler.

The period from the 1970s to the present has been the richest and most successful scientifically and in terms of scientific publications. Scientific and expert articles brought many innovations that are not only important for Slovenia but also for the Eastern AlpineDinaric region and, even more widely, for the Central European space. Many new syntaxons have been described, mostly of associations, but also lower ones (sub-associations, variants) and higher sinsystematic levels (sub-alliances and alliances). Among many phytocenology researchers with publications from this period are Marko Accetto, Andraž Čarni, Igor Dakskobler, Mitja Kaligarič, Petra Košir, Živko Košir, Lado Kutnar, Lojze Marinček, Aleksander Marinšek, Milan Piskernik, Andrej Seliškar, Urban Šilc, Sonja Škornik, Tone Wraber, Igor Zelnik, Mitja Zupančič.

After reform of the forestry services, there were ever fewer commissions for ecological evaluation of forest areas, until they finally dried up. A new methodology has emerged in Europe, focused on habitat types, which is less demanding, simplified and, therefore, more acceptable. 
